(Sage and Thyme), advance care planning and bereavement needs assessment.

Aim The aim of the education programme is to increase the knowledge, skills and confidence of the care staff which enables them to identify appropriate patients early and address the need for future planning as well as providing palliative and end of life care whilst supporting and involving families.

Method The education programmes are delivered in the care home and tailored to meet their specific needs. Working alongside care staff caring for our patients and families allows the hospice team and the staff to see the benefit of the education programme in practice and also to provide hands on 1: 1 education and support. This model of working also enables the team and staff to identify further educational opportunities.

Future planning with patients and families often takes place initially with the CNS until the staff feel confident. Using the wIPADS Framework has enabled staff to document and share these plans with the community MDT which has helped to reduce unnecessary admissions, investigations and treatments. Our patients often have multi-morbidities and parallel planning between specialities is essential in order to affirm life and prepare for death. The CNS and members of our family support team also provide carer support for families and on occasions for staff.

Results During the last 18 months the service has received approximately 180 referrals from our care home community of which 128 patients died. 126 patients died in the care home and two died in hospital. The enthusiastic care home staff supported by the hospice team and ongoing education programme has helped to reduce unnecessary admissions and ensures patient-centred care.

\section{P-210 TRUSTED ASSESSOR PILOT - MAKING SURE THAT PATIENTS ARE WHERE THEY NEED TO BE!}

Beverley Collins. ellenor, Kent, UK

\subsection{6/bmjspcare-2018-hospiceabs.235}

Background Many patients will unnecessarily wait too long for discharge from hospital resulting in a poor experience of the health/social care system, which may cause a reduction in their overall health outcomes (Emergency Care Improvement Programme, 2015). A pilot is being conducted to reduce numbers and waiting times of patients ready for discharge from hospital and facilitate their move back to their care home speedily, effectively and safely. A Trusted Assessor's (TA) role has been assigned and its role is to act as a central communications link, facilitator and trouble-shooter.

Aim The pilot aims to provide:

- Smoother transition between care providers thus improving the discharge of patients

- Potential reduction in bed days within an acute care setting following the timely discharge of patients involved with the pilot

- Evidence of how the TA model could work within care homes on a long term basis.

Methods Care home staff initiates referral to the TA about proposed hospital discharges. TA visits the hospital to assess patients admitted from a care home ensuring that all current end of life plans and clinical information are considered as discharge planning commences. TA liaises and confirms the patient's current condition can be managed by the care home and any equipment/medication is ordered prior to discharge. The TA is responsible for completing documentation for data review and audit trail.

Feedback Care home staff report communications have improved with the hospital because of intervention of the TA which keeps all parties in the discharge/admission loop. The hospital is monitoring potential reductions in bed days. Positive outcomes of pilot have helped build a new level of trust and co-operation between all parties.

Conclusion The impact of the pilot has been enhanced trust and working relationships for all stakeholders. Further explanation of the role is anticipated with recruitment of TA to cover more homes.

\section{P-211 THE MELODIC CARING PROJECT - INTRODUCING THE HEALING ELEMENTS OF MUSIC INTO ADULT HOSPICE CARE}

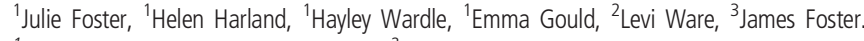
${ }^{1}$ Ashgate Hospicecare, Chesterfield, UK; ${ }^{2}$ Melodic Caring Project, Seattle, Washington, USA; ${ }^{3}$ Chesterfield College, Chesterfield, UK

10.1136/bmjspcare-2018-hospiceabs.236

Background The Melodic Caring Project (MCP) was created in 2010 when founder Levi Ware set up a live stream from a music concert for a local girl receiving chemotherapy. Staff at Chesterfield College, witnessed MCP and developed a learning opportunity in partnership with MCP for Media students to stream live music. The college contacted Ashgate Hospicecare to develop this project further for adult patients with life-limiting illnesses.

Aims

- To bridge the gap between music and patients by streaming live concerts to Ashgate Hospicecare

- To embrace the therapeutic properties of music to alleviate pain, anxiety and promote patient wellbeing (Harvard Men's Health Watch, 2011; Standley, 1986)

- To provide college students with regular broadcasting work experience.

Methods Chesterfield College arrange Artist/venue participation and share with Ashgate Hospicecare who identify patients to take part/have their names 'shouted out' on stage. Chesterfield College team attend and live stream the concert to Ashgate Hospicecare via a laptop. Patient/family feedback recorded by Ashgate communications team with consent.

Results

- Since December 2017, four live events have been successfully streamed to eight patients

- Patients and relatives report the benefit of this initiative bringing a feeling of normality back to their lives

- Nurses report a reduction in one patient's pain relief requirements leading up to and during the concert and another patient delayed her discharge home in order to take part.

Conclusion MCP provides a unique personalised experience for patients and their families and evaluates very well through patient/family feedback

Innovation Through support from MCP and Chesterfield College, Ashgate Hospicecare have successfully provided MCP 